\title{
Benefits derived from opportunistic survival- enhancing interventions for the Hawaiian monk seal: the silver BB paradigm
}

\author{
Albert L. Harting ${ }^{1, *}$, Thea C. Johanos ${ }^{2}$, Charles L. Littnan ${ }^{2}$ \\ ${ }^{1}$ Harting Biological Consulting, 8898 Sandy Creek Lane, Bozeman, Montana 59715, USA \\ ${ }^{2}$ Pacific Islands Fisheries Science Center, National Marine Fisheries Service, NOAA, 1845 WASP Blvd., Building 176, \\ Honolulu, Hawaii 96818, USA
}

\begin{abstract}
The cumulative benefits derived from historic small-scale, opportunistic interventions for the Hawaiian monk seal Monachus schauinslandi were assessed using multiple methods. The analysis focused on interventions undertaken to enhance survival of individual seals by reducing or eliminating immediate mortality risks. These interventions included dehookings, disentanglements, removing seals from high predation zones, medical interventions, and related activities. A total of 885 interventions occurred range-wide from 1980 to 2012. These included 645 interventions classified as mitigating medium- to high-risk threats, involving 532 different seals. In the Northwest Hawaiian Islands, where most of these interventions took place, we found a significant relationship between the number of interventions conducted annually and duration of field effort. The survival and reproduction of the intervention seals were tracked through multiple generations, using (1) known survival and reproduction of intervention seals, and (2) expected survival and reproduction as determined using demographic rates estimated for the population at large. This analysis indicated that $17-24 \%$ of the 2012 population comprised either intervention seals or descendants of intervention seals. If seals included in a multiyear (1984-1992) rehabilitation and captive care effort are also included, this proportion increases to $32 \%$. These findings demonstrate the important link between the sustained population assessment field effort, the number of interventions that are enabled in association with those efforts, and the current status of the monk seal population. In contrast to a metaphorical 'silver bullet' whereby a result is achieved through a single (or a few) highly impactive tools, we liken our success in applying multiple interventions to a fusillade of many silver BBs $\stackrel{1}{ }$.
\end{abstract}

KEY WORDS: Interventions · Hawaiian monk seal · Endangered species · Population recovery

\section{INTRODUCTION}

The Hawaiian monk seal Monachus schauinslandi is among the most endangered marine mammals in the world. The species is listed as 'endangered' under the Endangered Species Act (41 Federal Register 51611), 'depleted' under the Marine Mammal

1BBs are small round 'shot' used in certain types of recreational guns.
Protection Act, and 'Critically Endangered' by the IUCN. The demography, life history, and status of the monk seal have been investigated in the remote Northwestern Hawaiian Islands (NWHI) for over $30 \mathrm{yr}$ and the litany of threats confronting the species in that portion of its range is well documented (e.g. Ragen \& Lavigne 1999, Antonelis et al. 2006, Lowry et al. 2011). Despite this wealth of information, the species continues to decline in abundance at a rate of approximately $3.4 \%$ per year (Carretta et al. 2012). 
Recently, there have been encouraging signs that may portend moderation in the rate of decline for the species. These signs include improvements in juvenile survival at some NWHI sites (National Marine Fisheries Service, unpublished data), as well as an increase in abundance in the Main Hawaiian Islands (MHI) (Baker \& Johanos 2004, Baker et al. 2011b). However, at this time, these factors alone are insufficient to reverse the long-term downward population trajectory.

For some species at risk, recovery programs have been designed around one or several high-impact interventions that form the cornerstone of the program, and around which other actions can be tiered to augment or reinforce the net benefit. Those pivotal actions, which may be complex and require considerable investment, are intended to either directly ameliorate the primary factor(s) constraining population growth or, if that is not feasible, provide effective mitigating benefits that enable the species to grow despite persistent pressure from the recognized risks. Familiar examples of species for which the recovery program was (or remains) contingent on a limited set of focal recovery initiatives include: DDT regulation for the bald eagle (Brown 1976) and peregrine falcon (Cade et al. 1997); captive breeding for the black-footed ferret (Lockhart et al. 2005) and the California condor (Toone \& Wallace 1994); reintroduction of the gray wolf into Yellowstone National Park (Smith et al. 2003); and harvest regulation for the American alligator (Woodward et al. 1992).

In contrast to the preceding examples, the monk seal is not among those species for which a single pivotal conservation measure has emerged as the unequivocal centerpiece upon which to construct the recovery platform (NMFS 2007). A number of measures, historical and current, have been undertaken to help arrest the species' population decline, and these have certainly provided incremental benefits. These measures, as diffuse as the litany of threats confronting the species, include removal of aggressive males (Johanos et al. 2010), rehabilitation and in situ 'headstart' programs for young seals with poor survival prospects (Gilmartin et al. 1986, 2011), mitigations to reduce shark predation on pups (Gobush \& Farry 2012), marine debris removal (Donohue et al. 2001), parasite reduction (Gobush et al. 2011), proposed expansion of translocation of juveniles to enhance survival (Baker et al. 2011a, 2013), and various other measures (Lowry et al. 2011). These interventions have been implemented for various lengths of time, for example, on an ex- perimental basis to assess their efficacy (such as deworming and headstart, neither of which proved to be highly effective), as remedial measures to address low survival (rehabilitation), to target ephemeral mortality risks (aggressive male removal), or as long-term measures to address chronic threats (marine debris removal and predation mitigation).

Most of the measures described above were preplanned, required dedicated logistical support, and were instituted as distinct initiatives to address a recognized threat to survival of multiple seals. However, small-scale, opportunistic interventions to address specific mortality risks affecting one or several seals are also regularly conducted. These actions, conducted during annual field research in the NWHI or year-round in the MHI, include disentanglements, reuniting mother-pup pairs, dehookings, treatment of wounds and abscesses, and similar interventions. While the benefits derived from the specific efforts listed above (i.e. rehabilitation, deworming, etc.) have largely been evaluated, there has been no concerted attempt to assess and quantify the cumulative benefits accrued from these many opportunistic interventions undertaken over many years. In this paper, we evaluate the effects of these historical interventions by examining the numbers of seals directly or indirectly affected by these actions. We also predict the likely returns of these ongoing actions on the present population status.

\section{MATERIALS AND METHODS}

Remote field camps were deployed to 6 main breeding subpopulations in the NWHI during most years since the mid-1980s. The duration of the field season varied by site and year, but was generally 3 to $4.5 \mathrm{mo}$ at the more populous sites. Primary tasks included tagging of weaned pups; behavioral observations; collecting assessment data for population enumeration, calculating trend indices, and demographic rates; and documenting known mortality risks and, where appropriate, reducing those risks through direct intervention. This intensive, regular field effort resulted in a high probability (>90\%) that living seals were resighted at least once during a field season (Baker \& Thompson 2007) and provided an exceptionally robust demographic database on which to tier our analysis. Demographic data for the small but growing population of seals in the MHI were collected jointly by staff and by a network of trained volunteer observers (Baker \& Johanos 2004, Baker et al. 2011b). 


\section{Types of intervention}

Our analysis covers opportunistic interventions range-wide, but the emphasis is on the NWHI, where the vast majority of such interventions have historically occurred. We only analyze direct interventions which were undertaken to address a survival risk to a particular seal or seals, and which typically involved handling of a seal. In this context, 'handling' is used loosely to include not only direct physical contact but also indirect contact in which a seal's behavior or location is altered or modified through human intervention, such as hazing (i.e. herd or harass, as necessary) a seal away from an imminent threat. In contrast, indirect interventions are those that are undertaken to ameliorate potential or dispersed risks (such as removing marine debris from beaches and coral reefs, regulating fisheries, controlling public access to sensitive seals or areas, and removing aggressive males or predatory sharks) and are not assessed herein. This is necessary because measuring the benefits associated with indirect interventions is highly subjective and uncertain. In contrast, the benefit of the direct interventions analyzed in this paper is more certain and quantifiable.

We identified 7 types of opportunistic 'survivalenhancement' intervention for this analysis: (1) disentangling/dehooking (with or without restraint); (2) rescue from entrapment or out-of-habitat situation; (3) translocation between islets or, less frequently, between breeding sites; (4) human-assisted pup switch/pup reunification with mother; (5) detaching an umbilical cord; (6) veterinary/medical intervention or treatment; and (7) other recovery actions to resolve an immediate life-threatening situation, such as hazing off boat ramp, hazing a male that is attacking a pup, etc.

Individual intervention events were assigned a severity code to indicate the relative risk posed by the threat being mitigated (Table 1). Each of the 7 above intervention types could, depending on the

Table 1. Severity codes for denoting relative risks associated with intervention (handling) events for Hawaiian monk seals Monachus schauinslandi

\begin{tabular}{cl}
\hline Code & Definition \\
\hline$\leq 0$ & No effect $(=0)$ or negative effect on survival $(<0)$ \\
1 & Possibly improved chance of survival \\
2 & Probably improved chance of survival \\
3 & Seal would have almost certainly died without \\
& action, increased chance of survival
\end{tabular}

specific scenario, assume different severity levels, but in most cases involved life-threatening situations belonging to the 2 most severe categories (Severity 2 and 3: Table 1). Generic guidelines for the case-specific assignment of severity codes were developed, but some discretion remained with the original observer or reviewer for assessing the severity and probable outcome associated with each situation. Cases occurring prior to 1995, when standardized coding of intervention events was instituted, were retrospectively categorized and coded from descriptions in field notes and other sources on file.

In the NWHI, the opportunity to conduct survivalenhancing interventions was contingent on field team presence in seasonal camps. We therefore investigated the relationship between field effort and the number of interventions conducted each year. For this purpose, effort was defined as the sum of the effort days at all NWHI sites combined, and the relationship was evaluated using simple linear regression. The situation in the MHI differed in that year-round observations and volunteer reporting enabled interventions at any time of year, with less direct dependency on staff observations or field effort. Therefore, we did not attempt to evaluate the relationship between number of interventions and effort in the MHI.

\section{Lineage analysis}

We estimated the numbers of seals alive (as of 2012), which had either been handled for interventions or were descended from an intervention seal. This estimate extended to 3 generations, hereafter referred to as the handled seals ('parents' for purposes of the lineage analysis), the F1 (progeny of the intervention seals) and the F2 generation (progeny of the F1). This lineage analysis was approached in 2 ways. The first approach relied on direct observations (survival and reproduction) for known seals as compiled from historical data archived in the monk seal database. That is, we tracked the fate of individual seals throughout their lifespan to determine how many intervention seals remained in the population in 2012, whether they produced known progeny (first or second generation), and to determine whether those descendants were also in the current population. The shortcoming of this approach is that the historical reproductive data are incomplete or limited due to uncertain maternity and incomplete temporal and spatial coverage (Harting 2002, Harting et al. 2007). Consequently, counting only known offspring underestimates the actual reproduction, and the abil- 
ity to track lineages through multiple generations becomes unreliable.

Our second approach circumvented the observability bias by estimating the expected number, survival, and reproduction of F1 and F2 seals using demographic rates for the population at large. This approach required the assumption that the survival and reproductive rates of the intervention lineage seals did not differ from those of other seals in the population. The age-specific survival rates used for this approach were derived by pooling tag-resight data over all sites and years. Two contrasting sets of reproductive rates (for Laysan Island [LAY] and French Frigate Shoals [FFS]) were used to estimate F1 and F2 reproduction. These 2 sites have the longest and most complete reproductive data sets, and represented the extremes (highest and lowest, respectively) of the fitted rates for the NWHI (Harting et al. 2007).

\section{RESULTS}

\section{Number of survival-enhancing interventions}

Between 1980 and 2012, 885 interventions belonging to one or more of the 7 survival-enhancing types (Table 2) occurred, including 698 incidents to mitigate risks of Severity 2 or 3 (Table 3 ). These interventions involved 645 individual seals (i.e. individually distinguishable seals, having either a permanent or withinseason temporary ID) for all severities, and 532 seals for Severity 2 and 3. The majority mitigated entanglements in marine debris or hookings, or involved translocating animals from higher- to lower-risk areas.

Table 2. Number of occurrences for the 7 survival-enhancing categories as recorded for 885 interventions, 1980-2012, for Hawaiian monk seals Monachus schauinslandi. Note that some events were classified with more than one code so that the total number of occurrences from column 2 exceeds 885 . All severities (0-3) are included

\begin{tabular}{|lr|}
\hline Description & $\begin{array}{r}\text { No. of } \\
\text { events }\end{array}$ \\
\hline Disentangling/dehooking (with or without restraint) & 275 \\
Rescue from entrapment or out-of-habitat situation & 37 \\
Translocation between islets or large-scale movement & 284 \\
Human-assisted pup switch/pup reunites & 113 \\
Detaching of umbilical cord & 25 \\
Vet/medical intervention or treatment & 59 \\
Other recovery action to resolve an immediate life threatening & 120 \\
situation; can include hazing off boat ramp, hazing a male & \\
off a pup or similar & \\
\hline
\end{tabular}

Table 3. Number of interventions and number of permanently identified Hawaiian monk seals Monachus schauinslandi in each severity category. Second column also gives the number in each category by region (Northwestern Hawaiian Islands [NWHI] or Main Hawaiian Islands [MHI]) in parentheses. Individual seals may be involved in multiple interventions of different severities. Here, seals are tallied in 1 row only, corresponding to the highest severity level of all interventions they were involved in

\begin{tabular}{|lcc|}
\hline $\begin{array}{l}\text { Severity } \\
\text { level }\end{array}$ & $\begin{array}{c}\text { No. of interventions } \\
\text { (NWHI, MHI) }\end{array}$ & $\begin{array}{c}\text { No. of seals } \\
\text { (females) }\end{array}$ \\
\hline 0 & $90(66,24)$ & $29(10)$ \\
1 & $97(55,42)$ & $51(30)$ \\
2 & $213(177,36)$ & $130(73)$ \\
3 & $485(466,19)$ & $402(209)$ \\
Total & $885(764,121)$ & $612(322)$ \\
\hline
\end{tabular}

The number of interventions generally increased over the years that regular field camps were deployed in the NWHI (Fig. 1). However, there was considerable scatter in the pattern as field teams addressed unusual or specific mortality risks at some sites or in some years. Examples of specific interventions that contributed to single- or multiple-year spikes in numbers of survival-enhancing interventions included mitigations to reduce shark predation risks on pups at FFS (especially 2002-2004) and efforts to haze aggressive males away from weaned pups at Kure Atoll (2010-2011).

Effort has been consistently high at most sites since the early 1990s, but has become somewhat irregular in recent years. A regression of the number of survival-enhancing events on annual effort (sum of field season duration at all sites) was significant when all sites were combined $\left(\mathrm{p}=0.03, F_{1,30}=5.372\right)$. The relationship was improved when FFS, where interventions to address shark predation typically involved additional dedicated personnel, was omitted from the analysis $\left(\mathrm{p}=0.0003, F_{1,30}\right.$ $=16.595$; Fig. 2).

\section{Lineage analysis}

There were 532 uniquely identifiable seals involved in survivalenhancing interventions of Severity 2 and 3. Of those handled seals, 139 survived to 2012, including 71 females (Table 4). Through 2012, the female intervention seals (including those alive in 2012 as well as those 


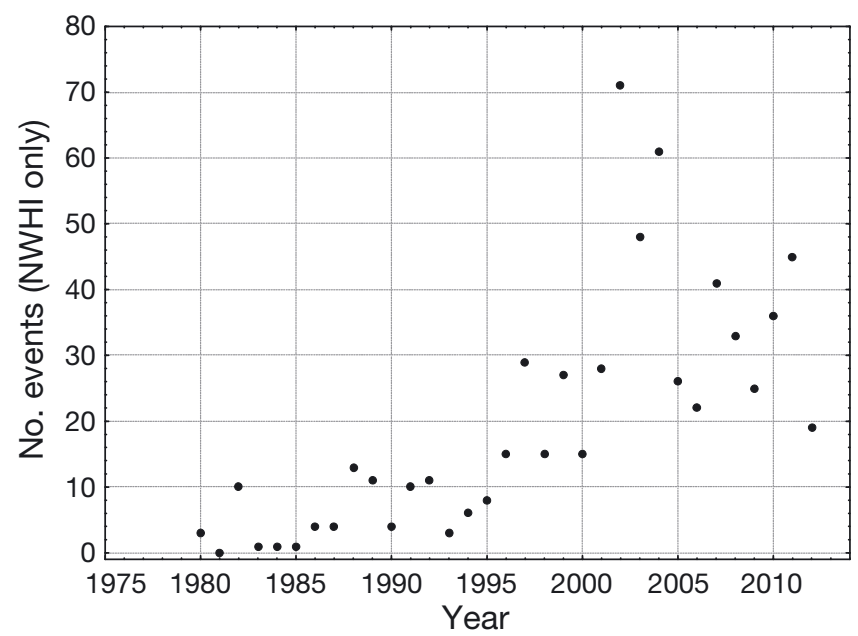

Fig. 1. Number of survival-enhancing interventions (Severity 2 and 3, see Table 1) to benefit Hawaiian monk seals Monachus schauinslandi conducted in the Northwest Hawaiian Islands. (NWHI)

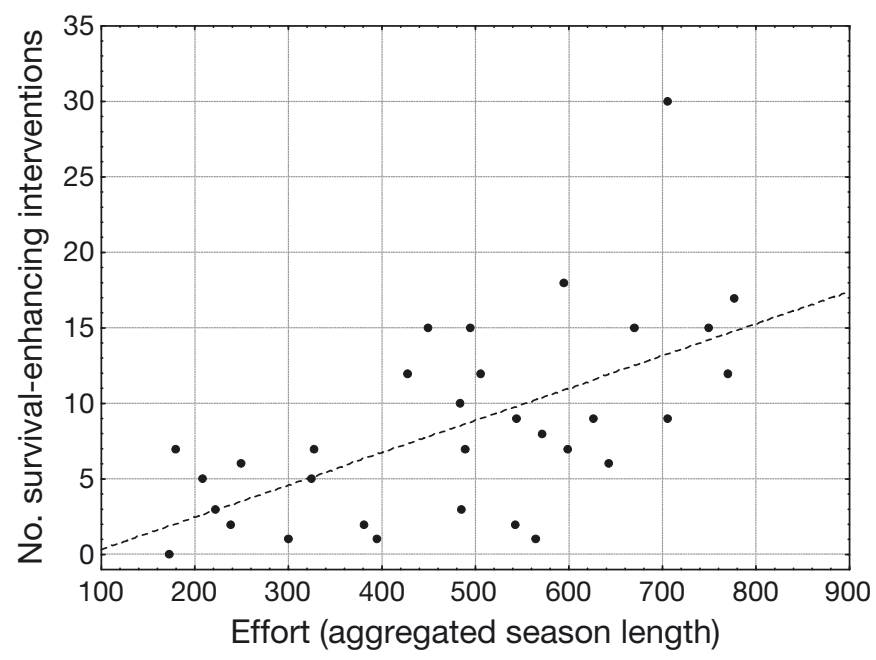

Fig. 2. Number of survival-enhancing interventions (Severity 2 and 3, see Table 1) to benefit Hawaiian monk seals Monachus schauinslandi versus aggregated field effort in the Northwest Hawaiian Islands, excluding French Frigate Shoals, 1980-2012 (dashed line: linear regression, $\mathrm{p}=0.0003$, $\left.F_{1,30}=16.595\right)$

that had previously died) produced 147 known pups, with 54 of those F1 descendants still alive in 2012, including 29 females. Extending the analysis one additional generation (F2), there were 15 known pups born to F1 females, with 5 of those alive in 2012, including 1 female. Combining all 3 generations gives 694 seals known to belong to the intervention lineages, with 198 still alive, including 101 females. These estimates are biased low because, although a parturition was confirmed (by observing an intervention seal tending a pup), many pups were not
Table 4. Lineage analysis for Hawaiian monk seals Monachus schauinslandi involved in survival-enhancing interventions, using 3 different methods: known ID seals (known survival and maternity of F1 and F2 generations, with number of females in parentheses); expected production using Laysan Island (LAY) reproductive rates; and expected production using French Frigate Shoals (FFS) reproductive rates. The latter 2 methods applied age-specific survival rates for the F1 and F2 generations as estimated by pooling observed survival over all Northwest Hawaiian Islands sites and years. Percentages in the last column represent the proportion of the 2012 monk seal population comprised of intervention lineage seals, as computed for each of the 3 methods

\begin{tabular}{|lcc|}
\hline & $\begin{array}{c}\text { No. of seals } \\
\text { handled or born }\end{array}$ & $\begin{array}{c}\text { No. alive } \\
\text { in } 2012\end{array}$ \\
\hline Known IDs only & & \\
Handled seals & $532(282)$ & $139(71)$ \\
F1 & $147(74)$ & $54(29)$ \\
F2 & $15(8)$ & $5(1)$ \\
Total & $694(364)$ & $198(101)(17 \%)$ \\
High reproductive estimate (LAY rates) & \\
Handled seals & 532 & 139 \\
F1 & 195 & 97 \\
F2 & 59 & 35 \\
Total & 786 & $271(24 \%)$ \\
Low reproductive estimate (FFS rates) & \\
Handled seals & 532 & 139 \\
F1 & 131 & 64 \\
F2 & 25 & 14 \\
Total & 688 & $217(20 \%)$ \\
\hline
\end{tabular}

assigned permanent IDs (by tagging or natural markings) until after weaning, at which time their maternity often becomes uncertain. Only those pups that we could confidently associate with an intervention seal were admitted to our analysis.

In contrast to known observed births, the expected production by intervention seals, as calculated using the LAY fitted age-specific reproductive curve, was approximately 195 F1 seals (as compared with the 147 observed F1 pups mentioned above), with 97 of those seals expected alive in 2012 (Table 4). The expected F2 production was 59 seals, with 35 likely to remain alive. Combining all 3 generations gives a total of 271 seals (139 handled seals + 97 F1 + 35 F2) expected in the current population. Applying the same procedure but substituting the FFS reproductive rates for the LAY rates yields 217 seals expected in the current population.

The 3 different methods for estimating the survival and reproduction of seals belonging to the intervention lineages yielded a range of 198-271 for the number of living seals which were either directly involved in survival-enhancing interventions or are descendants of those seals. One way to view the net effect 
achieved through many years of small-scale interventions is to consider the proportion of the current population which is directly or indirectly associated with these actions. The best estimate for monk seal abundance in 2012 (including the NWHI and MHI) is 1153 seals (J. D. Baker pers. comm.). Using this value, the 198-271 seals either known or expected (from applying estimated demographic rates) to be alive in 2012 equates to $17-24 \%$ of the population.

\section{DISCUSSION}

Those charged with recovery of endangered species, using finite and often diminishing resources, must grapple with the difficult task of determining what conservation measures will yield the greatest demographic returns per unit investment. Consequently, new recovery initiatives, particularly those that are controversial or will require substantial commitment of resources, should undergo a rigorous preevaluation of their likely contribution to the species' recovery (e.g. for monk seals, Baker et al. 2013, NMFS 2014).

Sophisticated new approaches for the quantitative evaluation of alternative management plans, such as Management Strategy Evaluation (MSE; e.g. Smith et al. 1999), have been widely adopted in fisheries management programs and, more recently, are being applied to aid management decisions for other taxa (e.g. Milner-Gulland et al. 2010). We anticipate that MSE and its kindred techniques will become increasingly common for elucidating the expected returns from high-investment initiatives in wildlife conservation. In contrast, the interventions we examined here were undertaken opportunistically and hence were not preceded by a formal evaluation to predict their benefits. However, because these actions were conducted in tandem with ongoing field work, they were relatively inexpensive and this retrospective evaluation is an acceptable alternative to the preferred paradigm of rigorous pre-evaluation.

It is reasonable and appropriate to ask how much has actually been achieved through the considerable investment in several decades of field presence and core research for the Hawaiian monk seal. Data on life history and demographics are of value only insofar as they contribute to the welfare of the species, as evidenced by the translation from data to conservation initiatives. In that context, conservationists are obliged to continually reevaluate their priorities and conduct triage on those components of their programs which have no discernible link to population recovery, and which arguably consume resources that might be redirected to greater advantage (Bottrill et al. 2008). We are heartened by the findings reported herein because they reinforce our intuition that, in addition to the wealth of scientific data on monk seal biology which has been amassed over the last $30 \mathrm{yr}$, the greater goal of monk seal recovery has also been incrementally enhanced through the sustained field efforts. Arguably, even if purely research objectives could be achieved through an abbreviated field effort, the associated forfeiture of opportunistic interventions would hinder the species' recovery.

Our analysis indicated that the number of intervention lineage seals which were either known or expected to have been alive in 2012 comprises $17-24 \%$ of the current population. The lower value, $17 \%$, is derived from tracking seals with known IDs and is certainly an underestimate, while the $24 \%$ could arguably err on the high side if the demographic performance of the handled seals and their offspring was less favorable than that estimated for LAY seals. Using the FFS rates gives an intermediate value of $20 \%$. While there are other elaborations and refinements that could be incorporated into this analysis, each with its own set of caveats and assumptions, we believe that the multiple methods we present provide a reasonable range from which to gauge the probable cumulative effects of the interventions.

These findings suggest that opportunistic interventions have been instrumental in preserving a substantial number of seals in the population and have thereby constrained the rate of decline. We have been careful to avoid overreaching by asserting that a substantial proportion (17-24\%) of the population owes its existence to the sustained effort expended toward small-scale interventions, and acknowledge that there is uncertainty regarding the ultimate outcome for each situation had no intervention occurred. Some risks would have undoubtedly been resolved with no intervention (e.g. a seal that managed to free itself from an entanglement), but many others would likely have culminated in serious impairment or death. Limiting the analysis to incidents of Severity 2 and 3 eliminated much of this uncertainty, and helps to define a likely lower bound for assessing the effectiveness of these interventions.

We observed a strong relationship between the number of interventions and the aggregate length of the annual field seasons in the NWHI. The ability to conduct small-scale opportunistic interventions in the NWHI is contingent on researchers' presence there, which, in most years, is limited to several months from spring through late summer. We can 
speculate as to how many additional interventions might accompany longer field seasons, but it is noteworthy that most of the attrition in numbers of young seals occurs during the 'observational shadow' between the end of one field season and commencement of the next. However, limited data from extended field seasons suggest that the frequency of interventions would decline during the non-pupping seasons, although risks such as hookings and entanglements are likely to persist throughout the year. In the MHI, our ability to engage in small-scale interventions is limited more by spatial access than by temporal limitations. Hazards exist year round, although in differing intensities, but many seals haul out in remote areas of the MHI that are not patrolled on a regular basis and hence remain inaccessible for either observation or, where warranted, intervention.

The benefits we describe, while considerable, do not capture the full breadth of activities or outcomes associated with monk seal conservation. In addition to the previously mentioned interventions (headstart, rehabilitation, and removal of aggressive males and/or sharks), a broad array of habitat protection measures have also been implemented, including designated fishery exclusion zones (Antonelis et al. 2006) and limits on beach access in areas deemed sensitive for seals. These activities have served, singly or in concert, to preserve seals in the population but, for most of these actions, it is difficult to fully quantify or estimate their contribution in terms of the number of seals added or retained in the population. However, a similar lineage analysis as presented here was previously conducted with regard to the rehabilitation program (Gilmartin et al. 2011). Including those rehabilitated female seals with the intervention lineage already presented here brings the upper range of those 2 lineages combined to $32 \%$ of the 2012 population.

The most important conclusion to emerge from our analysis is this. In our quest to elucidate and undertake the more ambitious recovery actions - those that are grandiose in scope and potentially lucrative in terms of demographic rewards - we should not dismiss the incremental returns that accrue over time from many small-scale, seemingly insignificant interventions. While these may not be the sort of initiatives that are widely celebrated in the press or that garner exuberant accolades from fellow conservationists, they may prove cumulatively integral to the long-term recovery effort. Our analysis indicates that this is certainly true for the monk seal, and we suspect it is true for a host of other endangered species for which no silver bullet has been found to propel the species to- ward recovery. In cases such as ours, rather than an elusive silver bullet, we must rely instead upon a great many silver BBs - modest actions that serve to collectively fortify the population until such time as natural processes become favorable for population growth and eventual recovery.

Acknowledgements. None of the interventions described in this paper would have taken place without the dedicated effort by the many individuals who have served in the monk seal field camps over the last $30+$ years. Their vigilance and dedication in detecting and addressing survival risks is, as our analyses has demonstrated, key to the species' welfare. We also thank everyone in the NOAA Fisheries' Hawaiian Monk Seal Research Program for carefully reviewing the archival data to enumerate and classify all of the interventions reviewed in this paper. Jason Baker provided valuable suggestions throughout this project, including recommendations concerning the scope and approach, as well as reviews of the draft document. Finally, we thank Dr. Daniel Goodman (1945-2012), long-time monk seal advocate and a former member of the Hawaiian monk seal Recovery Team. It was Dan who wryly observed at one Recovery Team meeting: 'Data for data's sake is seductive, but the objective is recovery, rather than the most perfectly chronicled decline in history.' It is in that spirit that these interventions, rescuing one seal at a time but always mindful of their incremental role in species recovery, were undertaken.

\section{LITERATURE CITED}

Antonelis GA, Baker JD, Johanos TC, Braun RC, Harting AL (2006) Hawaiian monk seal (Monachus schauinslandi): status and conservation issues. Atoll Res Bull 543:75-101

> Baker JD, Johanos TC (2004) Abundance of the Hawaiian monk seal in the main Hawaiian Islands. Biol Conserv 116:103-110

Baker JD, Thompson PM (2007) Temporal and spatial variation in age-specific survival rates of a long-lived mammal, the Hawaiian monk seal. Proc Biol Sci 274:407-415

Baker JD, Becker BL, Wurth TA, Johanos TC, Littnan CL, Henderson JR (2011a) Translocation as a tool for conservation of the Hawaiian monk seal. Biol Conserv 144: 2692-2701

Baker JD, Harting AL, Wurth TA, Johanos TC (2011b) Dramatic shifts in Hawaiian monk seal distribution predicted from divergent regional trends. Mar Mamm Sci 27:78-93

Baker JD, Harting AL, Littnan CL (2013) A two-stage translocation strategy for improving juvenile survival of Hawaiian monk seals. Endang Species Res 21:33-44

Bottrill MC, Joseph LN, Carwardine J, Bode M and others (2008) Is conservation triage just smart decision making? Trends Ecol Evol 23:649-654

Brown L (1976) Birds of prey: their biology and ecology. Hamlyn, London

Cade TJ, Enderson JH, Kiff LF, White CM (1997) Are there enough good data to justify de-listing the American peregrine falcon? Wildl Soc Bull 25:730-738

Carretta JV, Oleson E, Weller DW, Lang AR and others (2013) U.S. Pacific Marine Mammal Stock Assessments: 2012. NOAA Tech Memo NMFS-SWFSC-504. US Department of Commerce, SWFSC, Santa Cruz, CA 
Donohue MJ, Boland RC, Sramek CM, Antonelis GA (2001) Derelict fishing gear in the Northwestern Hawaiian Islands: diving surveys and debris removal confirm threat to coral reef ecosystems. Mar Pollut Bull 42: 1301-1312

Gilmartin WG, Morrow RJ, Houtman AM (1986) Hawaiian monk seal observations and captive maintenance project at Kure Atoll, 1981. NOAA Tech Memo NOAA-TMNMFS-SWFC-59. US Department of Commerce, NMFS, Honolulu, HI

Gilmartin W, Sloan AC, Harting AL, Johanos TC, Baker JD, Breese M, Ragen TJ (2011) Rehabilitation and relocation of young Hawaiian monk seals (Monachus schauinslandi). Aquat Mamm 37:332-341

Gobush KS, Farry SC (2012) Non-lethal efforts to deter shark predation of Hawaiian monk seal pups. Aquat Conserv: Mar Freshw Ecosyst 22:751-761

Gobush KS, Baker JD, Gulland FMD (2011) Effectiveness of an antihelminthic treatment in improving the body condition and survival of Hawaiian monk seals. Endang Species Res 15:29-37

Harting AL (2002) Stochastic simulation model for the Hawaiian monk seal. PhD dissertation, Montana State University, Bozeman, MT

> Harting AL, Baker JD, Johanos TC (2007) Reproductive patterns of the Hawaiian monk seal. Mar Mamm Sci 23: 553-573

Johanos TC, Becker BL, Baker JD, Ragen TJ, Gilmartin WG, Gerrodette $\mathrm{T}$ (2010) Impacts of sex ratio reduction on male aggression in the Critically Endangered Hawaiian monk seal Monachus schauinslandi. Endang Species Res 11:123-132

Lockhart JM, Thorne ET, Gober DR (2005) A historical perspective on recovery of the black-footed ferret and the biological and political challenges affecting its future. In: Roelle JE, Miller BJ, Godbey JL, Biggins DE (eds): Recovery of the black-footed ferret: progress and continuing challenges. Proc Symp on the Status of the Black-

Editorial responsibility: Nils Bunnefeld, Stirling, UK footed Ferret and Its Habitat, Fort Collins, CO, 28-29 January 2004. US Department of the Interior, USGS Scientific Investigations Report 2005-5293, p 6-19

> Lowry LF, Laist DW, Gilmartin WG, Antonelis GA (2011) Recovery of the Hawaiian monk seal (Monachus schauinslandi): a review of conservation efforts, 1972 to 2010, and thoughts for the future. Aquat Mamm 37:397-419

Milner-Gulland EJ, Beatriz A, Bellard C, Blanchard J and others (2010) New directions in management strategy evaluation through cross-fertilization between fisheries science and terrestrial conservation. Biol Lett 6:719-722

NMFS (2007) Recovery plan for the Hawaiian monk seal (Monachus schauinslandi). 2nd revsn. National Marine Fisheries Service, NOAA, Silver Spring, MD

NMFS (2014) Final programmatic environmental impact statement for Hawaiian monk seal recovery actions. National Marine Fisheries Service, NOAA, Pacific Island Fisheries Science Center, Honolulu, HI

Ragen TJ, Lavigne DM (1999) The Hawaiian monk seal: biology of an endangered species. In: Twiss JR, Reeves $\mathrm{RR}$ (eds) Conservation and management of marine mammals. Smithsonian Institution Press, Washington, DC, p 224-244

Smith ADM, Sainsbury KJ, Stevens RA (1999) Implementing effective fisheries-management systems - management strategy evaluation and the Australian partnership approach. ICES J Mar Sci 56:967-979

Smith DW, Peterson RO, Houston DB (2003) Yellowstone after wolves. Bioscience 53:330-340

Toone WD, Wallace MP (1994) The extinction in the wild and reintroduction of the California condor (Gymnogyps californianus). In: Olney PJS, Mace GM, Feistner ATC (eds) Creative conservation: interactive management of wild and captive animals, Springer, New York, NY, p 411-419

Woodward AR, Moore CT, Delany MF (1992) Experimental alligator harvest. Final Report. Florida Game and Fresh Water Fish Commission, Tallahassee, FL

Submitted: March 5, 2014; Accepted: May 15, 2014

Proofs received from author(s): August 15, 2014 